\title{
Review
}

Pharmacology

\section{Neuronal Mechanisms and the Treatment of Motion Sickness}

\author{
F. Schmäl \\ Department of Otorhinolaryngology, Head and Neck Surgery, HNO-Zentrum Münsterland, Greven, Germany
}

\section{Key Words}

Motion sickness · Mechanisms · Prevention · Treatment ·

Drug treatment

\begin{abstract}
The aim of this review is to provide an overview of the physiological basis, clinical picture and treatment options for motion sickness. Motion sickness is a well-known nausea and vomiting syndrome in otherwise healthy people. The physical signs of motion sickness occur in both humans and animals during travel by sea, automobile or airplane and in space. Furthermore, some other special situations, such as simulators, the cinema and video games, have been described as causing pseudomotion sickness. Children between 2 and 12 years old are most susceptible to motion sickness, and women are more frequently affected than men. Predisposing factors include menstruation, pregnancy, migraines and possibly a side difference in the mass of otoconia in the vestibular organs. Therapy is directed towards decreasing conflicting sensory input, accelerating the process of adaptation and controlling nausea and vomiting. To control these vegetative symptoms, scopolamine and antihistamines are the most effective drugs.
\end{abstract}

Copyright $\odot 2013$ S. Karger AG, Basel

\section{KARGER}

E-Mail karger@karger.com

www.karger.com/pha

\section{Introduction}

Motion sickness is considered a physiological vertigo and is thus not a true sickness in the strict sense of the word but rather is a normal response to an abnormal situation. Motion sickness is caused by certain types of motion and is induced during passive locomotion in vehicles, generated by unfamiliar body accelerations, to which the person has not adapted, or by an intersensory conflict between vestibular and visual stimuli [1]. Motion sickness indiscriminately affects air, sea, road and space travelers. All individuals (humans and animals) possessing an intact vestibular apparatus can get motion sickness given the right quality and quantity of provocative stimulation, although there are wide and consistent individual differences in the degree of susceptibility [2,3].

The cardinal signs of motion sickness are nausea, vomiting, pallor and cold sweating. The associated reactions include sighing, yawning, hyperventilation, flatulence, loss of body weight, headache and drowsiness.

A functional vestibular system is a prerequisite for motion sickness. Subjects with nonfunctioning labyrinths are immune to motion sickness [4]. 
Table 1. Six types of sensory rearrangements that can provoke motion sickness [7]

\begin{tabular}{lll}
\hline Type of conflict & Category 1: & Category 2: \\
& conflict between visual (A) and vestibular/ \\
proprioceptive (B) signals & $\begin{array}{l}\text { conflict between canal (A) and otolith } \\
\text { (B) signals }\end{array}$ \\
\hline
\end{tabular}

\section{Type 1}

Input $\mathrm{A}$ and $\mathrm{B}$ simultaneously receive contradictory or uncorrelated information
Watching waves over the side of a ship

Looking out of the side or rear windows of a moving vehicle

Making head movements while wearing an

optical device that disturbs vision
Type 2

Input A signals in the absence of the expected B signal
Head movements made about some axis other than that of bodily rotation cross-coupled angular acceleration Low-frequency oscillation between 0.1 and $0.3 \mathrm{~Hz}$
Cinema sickness

Operating a fixed-base vehicle simulator with a moving visual display (simulator sickness) 'Haunted-swing' type of fairground device
Space motion sickness

Caloric stimulation of the outer ear

Positional alcoholic nystagmus associated with alcohol and heavy water

\section{Type 3}

Input $B$ signals in the absence of the expected A signal
Reading a map in a moving vehicle Riding in a vehicle without external visual reference

Being swung in an enclosed cabin
Rotation about an earth-horizontal axis Any rotation about an off-vertical axis

Counterrotation

\section{The Vestibular System}

In humans, a highly sophisticated mechanism for maintaining gaze (vestibulo-ocular reflex) and balance (vestibulospinal reflexes) during head and body movements has developed; the mechanism is dependent upon visual, vestibular and proprioceptive sensory information. The information is integrated in the central nervous system and is modulated by activity arising in the reticular formation, the extrapyramidal system, the cerebellum and the cerebral cortex.

Each vestibular labyrinth contains 5 vestibular receptors: 2 maculae of the otolith organs, which can be stimulated by linear acceleration in the horizontal (utricle) and vertical (saccule) direction, and 3 cristae ampullares of the semicircular canals, which detect angular accelerations in 3 different planes.

\section{Neuronal Mechanism of Motion Sickness}

Currently, motion sickness is thought to arise from conflicting information processed within a multimodal sensory system whose function is to determine the indi- vidual's motion relative to his/her environment. This has been termed 'neural mismatch theory' $[5,6]$.

For the past 4 decades, the sensory conflict theory, most extensively described by Reason and Brand [7], has provided a theoretical framework for understanding motion sickness.

According to the theory, motion sickness results when the brain receives conflicting information about body movements from the visual and vestibular receptors and the proprioceptive system ('sensory mismatch').

Most sickness-provoking sensory conflicts can be classified into two different categories:

(1) conflict between visual and vestibular/proprioceptive signals and

(2) conflict between canal and otolith signals.

Furthermore, for each sensory conflict category 3 subtypes of conflicts can be distinguished. From these 2 categories and 3 types of conflict, 6 basic conflict types can be derived in which motion sickness might reasonably be expected to occur (table 1). 


\section{Conflict between Visual and Vestibular/ Proprioceptive Signals}

\section{Type 1}

Type 1 conflict occurs when visual and vestibular receptors simultaneously signal motion but of an uncorrelated or incompatible type. One everyday example is a situation in which a man is standing on the deck of a sailboat and is looking down at the motion of the waves.

The same conflict occurred in a laboratory experiment of subjects wearing disturbing optical devices, which reversed and inverted the visual field. During this type of experiment, the vestibularly perceived motion is contrary to the movement seen in the visual field. However, the degree of visual distortion necessary to produce symptoms does not need to be as extreme as this. A change in corrective lens prescriptions is often sufficient to produce nausea during the early stages of transition.

Another conflict situation occurs if a person is looking out the side window of a moving vehicle. In this case, the perceived velocity is different from the viewed velocity.

\section{Type 2}

Type 2 conflict occurs when the visual receptors perceive a relative motion of large portions in the visual field, which is normally associated with simultaneous vestibular stimulation signaling head and/or body movements but where these latter movements are absent.

Because in this situation body motion is missing, Schmäl and Stoll [8] created the terms 'pseudokinetosis' and 'pseudomotion sickness' in 2000 to describe this special type of conflict.

The following situations represent this type of conflict: cinema sickness: in one study, observers were readily made motion sick by watching a film shot from a car driving down a winding mountain road [9];

simulator sickness: this form of motion sickness can be induced in the operators of fixed-base car or aircraft simulators in which a moving visual display simulates the outside world as it would be viewed from a vehicle in motion;

haunted swing: in one experiment, a swing was mounted in the center of a fully furnished room; when people took their seats on the swing, it was apparently put into motion; however, it was not the swing but the room that was in motion.

\section{Type 3}

This type of sensory conflict occurs in the presence of a vestibular stimulus while an expected correlated visual signal is absent. Examples of situations that cause this conflict type include reading a map in a moving vehicle, riding in a vehicle without external visual references and being swung in an enclosed cabin.

\section{Conflict between Canal and Otolith Signals (Intralabyrinthine Conflict)}

Type 1

Type 1 conflict occurs when canals and otoliths simultaneously signal contradictory information concerning the position and motion of the head. One typical example of this type of sensory conflict is the vestibular coriolis reaction (coriolis or cross-coupled stimulus), which occurs when a test subject, seated on a chair rotating at constant speed (e.g. in the horizontal plane), moves his/her head about an axis other than the axis of rotation (e.g. forward and backwards).

\section{Type 2}

Type 2 sensory conflict is characterized by the presence of a canal signal in the absence of an expected correlated signal from the otoliths. This conflict occurs during the following situations:

microgravity condition: on earth, each stimulation of a semicircular canal during head movements is combined with corresponding otolith stimulation; under microgravity conditions in space when gravity is nearly absent, no otolith signal occurs during canal stimulations in the context of head movements;

caloric stimulation of the horizontal semicircular canals: even in an earth-based laboratory, applying unilateral caloric stimulation to one horizontal semicircular canal can create a type 2 canal-otolith conflict between the stimulated semicircular canal and the nonstimulated otolith organs; on the other hand, unilateral caloric stimulation can cause a canal-canal conflict between the stimulated and nonstimulated horizontal semicircular canals.

\section{Type 3}

This type of motion sickness is provoked by the presence of an otolithic signal in the absence of an expected backup signal from the semicircular canals. This type of sensory conflict occurs only in the laboratory, namely during rotation (at constant angular velocity) about an earth-horizontal axis (barbecue rotation) and during counterrotation:

barbecue rotation: during this rotation with constant angular velocity, without angular acceleration and, thus, 
without stimulation of the semicircular canals, the orientation of the otolith organs in relation to the gravity vector is permanently changing, and consequently otolith stimulation without canal stimulation occurs;

counterrotation: this stimulation can be performed with a device, which consists of a secondary turntable mounted on a centrifuge with a short radius; this secondary turntable revolves at the same rate as the main centrifuge but in the opposite direction.

In this way, the test subject is seated on the secondary turntable and faces the same direction because the counterrotation of the secondary turntable cancels out the rotation of the primary drive axis.

Some work groups $[6,10,11]$ postulate that in some cases of motion sickness, the conflict originates from differences between the sensory information received presently (visual and vestibular receptors receive different information about head and body movements) and stored experience (congruent visual and vestibular input). Pitman and Yolton [12] used the term 'exposure history' for this stored experience.

Some authors [13-15] demonstrated different otoconial masses between the right and left sides in their experiments with fish. The utricle appears to play a more important role in this difference than the saccule. These authors assume that a misbalanced sensitivity of the statolith organs occurs but is completely compensated for by the vestibular system as long as physiological motion patterns take place. Decompensation leads to motion sickness under nonphysiological motion patterns.

Even in humans [16, 17], a significant correlation between otolith asymmetry and sensitivity to space motion sickness in astronauts has been found.

However, others [18] conclude that the otolith asymmetry between both sides with regard to the close relationship of utricular otolith weight might not be the main factor inducing motion sickness. With regard to this conclusion, tests of utricular (ocular vestibular-evoked myogenic potentials) and saccular (cervical vestibularevoked myogenic potentials) function showed no significant side differences in otolith response $[19,20]$.

Furthermore, some authors [21, 22] have postulated a possible genetic influence on susceptibility to motion sickness because of a recently reported association between genetic polymorphism of the $\alpha_{2}$-adrenergic receptor and increased autonomic response to stress and motion sickness [23].

\section{Motion Sickness Susceptibility}

A common pattern of all the motions that induce motion sickness is a repetitive linear or angular acceleration of the head. The greatest incidence of seasickness was found at a linear vertical frequency of about $0.2 \mathrm{~Hz}$, increasing with the acceleration level from a threshold value of $0.1 \mathrm{~m} \cdot \mathrm{s}^{-2}$ [23].

However, there are clearly wide individual differences in motion sickness susceptibility.

To quantify this susceptibility, it is possible to measure how long a test subject can endure a sensory conflict, to analyze the strength of a motion sickness-provoking stimulus or to quantify the observed vegetative symptoms.

To produce the symptoms of motion sickness, different devices have been developed, e.g. apparatuses for barbecue rotation, off-vertical axis rotation and dynamic posturography with simultaneous presentation of incongruent visual stimuli [24].

However, the most commonly used devices are those able to produce a coriolis- or cross-coupled stimulus. For example, a rotation chair (rotating about an earth-vertical axis) allows the test subject to simultaneously perform head movements in the frontal plane (up and down; Lansberg test) $[25,26]$.

About $5-10 \%$ of all people are very susceptible to motion sickness, while the remainder only shows moderate susceptibility. Motion sickness susceptibility fluctuates with age [10]. Infants below the age of 2 years are generally immune to motion sickness, but susceptibility seems to be at the highest level between the ages of 2 and 12 . Beyond the age of 50, any type of motion sickness is very rare.

Chinese individuals show a higher susceptibility to motion sickness than Caucasians [27], and women appear to be more susceptible to motion sickness [28], especially during menstruation $[29,30]$ and pregnancy. Thus, a relationship between the female endocrine system and motion sickness has been found [31].

In contrast, Cheung et al. [32] were not able to prove that different phases of the menstrual cycle influence subjective symptoms of motion sickness.

Because $45 \%$ of patients with motion sickness have been shown to benefit from a placebo, there is evidence that psychological factors also influence motion sickness susceptibility [33].

However, the most important aspect with regard to motion sickness susceptibility is the contents of the 'exposure history' that represents stored experiences. 
Busoni et al. [34] analyzed the impact of motion sickness on the incidence of vomiting after routine surgery in children $(\mathrm{n}=420)$ who received general anesthesia and inguinal field block for common pediatric surgery. The children were randomly allocated into one of two groups (halothane or sevoflurane). In the postoperative period, the authors found that motion sickness-positive children vomited more than motion sickness-negative children, regardless of the inhalation anesthetic used. However, motion sickness-negative children displayed a higher incidence of vomiting when halothane was used rather than sevoflurane.

\section{Pseudomotion Sickness}

As mentioned above, the symptoms of motion sickness even occur when motion is signaled from visual input in the absence of expected vestibular signals. These movements of the visual field without the movement of the body have been reported in immobile people in widescreen movie theaters (cinema sickness), in flight simulators that include a large moving visual display (simulator sickness), during some types of computer games (game sickness) [35-37] and in virtual reality environments.

Because of the absence of acceleration stimuli on the vestibular organ, the term 'pseudokinetosis' or pseudomotion sickness was created [8].

Perhaps the earliest case of visually induced motion sickness was reported in 1894. A huge swing was mounted in the center of a fully furnished room. When subjects took their seats on the swing, the swing was apparently put in motion, but in reality, the room was swinging. After a few minutes under these conditions, some people suffered from nausea and dizziness [38].

Because labyrinth-defective subjects are immune to visually induced motion sickness, it is suggested that the stimulation of vestibular centers is responsible for this phenomenon [10].

Normally in the case of body movements, the visual and the vestibular receptors register comparable information about body motion, and the signals of both systems are therefore congruent. But people watching a film shot from a car driving down a winding mountain road were made motion sick because the motion signals of the visual system are incongruent with the absent signals of the vestibular system (body at rest).

\section{Central Structures Involved in Motion Sickness}

Kubo et al. [39] found reciprocal connections between the vestibular nuclei and the hypothalamus in their experiments. Even the hypophysis and the hypothalamus are involved in motion sickness; vasopressin neurons in the magnocellular-neurohypophyseal system were activated during motion-induced nausea [40], and during motion sickness-provoking stimuli, an increasing histamine level was demonstrated [41].

McIntosh [33] postulated that an emetic chemoreceptor trigger zone in the area postrema of the medulla oblongata is responsible for producing motion sickness. In animal experiments the destruction of this cerebral region eliminated motion sickness symptoms [42]. Supratentorial structures do not play an important role in producing motion sickness because the removal of the cerebrum in animals does not change motion sickness susceptibility [43].

In sum, the following structures appear to be vital links in the neural pathway responsible for motion sickness [12]:

vestibular apparatus (semicircular canals und otolith organs);

vestibulocochlear nerve;

vestibular nuclei in the brainstem;

nodulus and uvula of the cerebellum;

chemoreceptive trigger zone (medulla oblongata);

vomiting center (reticular formation);

hypothalamus;

efferents involved in the emetic response.

\section{Prevention and Treatment of Motion Sickness}

The best therapy for motion sickness is to escape the motion, but if this is not possible, the following therapeutic options are established in the prevention and/or treatment of motion sickness:

(1) behavior measures;

(2) adaptation;

(3) drug treatment.

\section{Behavior Measures}

To prevent symptoms of motion sickness, head movements should be avoided by holding the head against the back of a seat [10].

Visual information that is in agreement with information from the vestibular and other sensory receptors suppresses the symptoms of motion sickness, whereas incon- 
gruent information of the visual and vestibular system promotes nausea and vomiting. Therefore, subjects with seasickness should be placed on the deck and told to view the distant horizon. Furthermore, people who are highly susceptible to motion sickness should choose window seats on flights and when traveling by train.

In a car, for example, it is important to maintain a forward-looking gaze (just as the driver does most of the time) and to avoid sideways or backwards glances that present the brain with uncorrelated visual information [44].

Because ethanol leads to a disturbed visual suppression of vestibularly evoked eye movements, it is helpful not to drink alcohol to avoid motion sickness symptoms.

While smoking tobacco had a negative influence on the symptoms of motion sickness, tolerance to motion sickness was aided by short-term smoking deprivation [45].

Sleeping has a positive influence on motion sickness symptoms because sleeping reduces the excitability of the vestibular system and thus minimizes the sensory conflict.

Yen Pik Sang et al. [46] observed that controlled breathing and listening to music provided significant protection against motion sickness.

Acupuncture at the P6 or Neiguan point to treat nausea and vomiting has been practiced in China for many years. More recently, acupressure at P6 has been successfully used to decrease nausea in pregnancy and postoperative nausea and vomiting [47-50], but different results [51-56] were observed for decreased motion sickness. In this context, Stern et al. [57] found that an acuband worn on the wrist or forearm decreases motion sickness symptoms and the gastric activity that usually accompanies motion sickness, whereas Miller and Muth [58] found no significant effect of such a band compared to a placebo.

In contrast, Korean hand acupressure at the K-K9 point was effective in reducing nausea and subjective motion sickness symptoms during emergency trauma transport of patients with a high risk of motion sickness [59].

\section{Adaptation}

It is well known that repeated or continued exposure to motion results in a declining motion sickness response in most individuals. Adaptation is one of the most effective therapies for motion sickness.

While 'adaptation' means a decreased response following continuous stimulation of a receptor system, the reduction of neuronal activity after repeated stimulation is called 'habituation'.
When at sea in rough conditions, most people adapt within a few days [60]. But after disembarking from a ship for longer than 3 months, the adaptation disappears and increased motion sickness susceptibility is noted [2].

It is possible to distinguish 3 distinct stages in the temporal sequence of adaptive effects and aftereffects: initial exposure effects, the effects of continued exposure and aftereffects [7].

Furthermore, Reason and Brand [7] distinguished between 'sensory adaptation' (decreasing response following continuous stimulation of a receptor system) and 'protective adaptation' (adaptation to a sensory mismatch).

The adaptation is normally highly specific to the particular stimulus conditions under which it was acquired. Thus, it is possible that sailors who usually travel in large ships may become sick when transferred to small boats [33].

In helicopter simulator studies, experienced instructors, who had presumably acquired an adaptive change from flying helicopters, were found to be more susceptible to sickness in the simulator than student pilots [10].

The same phenomenon was observed in people who often drive cars and were tested in a car simulator. Presumably, a strong 'exposure history' seems to be responsible for this observation in trained people.

A stimulus with a gradual onset generates fewer symptoms and allows for more rapid adaptation than a stimulus with an abrupt onset [61].

The adaptation continues the longer and more frequently a special stimulus is given [7].

During their experiments at sea, Helling and Westhofen [62] observed that at the beginning of the voyage, professional seamen had a significantly lower gain in nystagmus in harmonic acceleration testing than in the inexperienced volunteers. During the voyage, all the professionals showed nearly constant gain values, while all of the inexperienced individuals showed a decrease in gain only during the acute symptoms. These results point to a central vestibular depression in adapted volunteers. No adaptation occurs in the absence of nausea-inducing head or body movements.

At least $5 \%$ of all humans with symptoms of motion sickness show no signs of adaptation.

Interestingly, active body movements favor adaptation rather than passively induced movements during experimentally induced visual disturbance by optical systems (inverting prisms) [63]. Therefore, an additional influence of the proprioceptive system must be assumed.

The adaptation effects can also be explained by the sensory conflict theory. In situations that commonly pro- 
duce sensory conflicts (sensory rearrangement) and motion sickness, the brain presumably stores appropriate traces, making the sensory conflict part of our 'exposure history'. Once this occurs, there is no conflict between our expectations and the sensory information received and thus, after some time, motion sickness symptoms no longer occur.

In this exposure history the used movement sample is reprogrammed, i.e. the sample comes to a reorientation. In the absence of this now integrated conflict situation, symptoms of motion sickness occur once more. This effect is called 'mal de débarquement', 'land sickness' or 'adaptive aftereffect' [7, 64]. These symptoms typically dissipate over several hours or days but can linger for weeks $[65,66]$.

Examples of these effects are land sickness experienced after a long time on a ship, or sickness in astronauts after returning to earth from a longer trip in space. This phenomenon may be caused by pseudohallucinations from vestibular memory [67].

\section{Drug Treatment}

The first use of drugs to prevent motion sickness was mentioned in 1869 in the Lancet, where, in an anonymous letter to the editor, a combination of chloroform and tincture of belladonna was recommended for motion sickness. The sensory-mismatch theory leads to 3 possible drug effects in patients with motion sickness:

the reduction of the incongruent information;

the faster update of the 'exposure history' and thus the acceleration of the adaptation processes;

the removal of vegetative symptoms.

Three neurotransmitters, histamine, acetylcholine and noradrenaline, play an important role in the neural processes of motion sickness, because antihistamines, scopolamine and amphetamine are effective in preventing motion sickness.

Histamine $\mathrm{H}_{1}$ receptors are involved in the development of motion sickness signs and symptoms, including emesis. Upon provocative motion stimuli, a neural mismatch signal activates the histaminergic neuron system in the hypothalamus, and the histaminergic descending impulse stimulates $\mathrm{H}_{1}$ receptors in the brainstem's emetic center. The histaminergic input to the emetic center through $\mathrm{H}_{1}$ receptors is independent of dopamine $\mathrm{D}_{2}$ receptors in the chemoreceptor trigger zone in the area postrema and serotonin $5-\mathrm{HT}_{3}$ receptors in the visceral afferent, which are also involved in the emetic reflex.

Antihistamines block emetic $\mathrm{H}_{1}$ receptors to prevent motion sickness. Scopolamine prevents motion sickness by modifying neural stores to reduce the neural mismatch signal and by facilitating the adaptation/habituation processes. The noradrenergic neuron system in the locus caeruleus is suppressed by the neural mismatch signal. Amphetamine antagonizes mismatch-induced suppression of noradrenergic neural transmission, resulting in motion sickness prevention [68].

It is assumed that all anti-motion-sickness drugs affect a hypothetical equilibrium between the central cholinergic and adrenergic systems, which is influenced by movements [69].

Because vestibular stimulation is essential for motion sickness to occur, it is assumed that all agents that have some central or peripheral vestibular suppressant effect will be effective in the prevention or active treatment of motion sickness [23].

Several factors should be considered before deciding which drug should be prescribed to an individual. This is because motion sickness depends on many different factors, such as individual susceptibility and the type, magnitude and duration of the stimulus. It also makes a difference whether the individual is a ship's passenger who can rest or sleep during the trip and tolerates the undesirable side effects of anti-motion-sickness drugs, such as drowsiness and decrease in psychomotor performance [70], or an air or naval crew member who has to be completely alert during the voyage. The approach will also be different if the goal is to prevent motion sickness or to actively treat it when signs and symptoms have already appeared [23].

Medication is most effective when taken before exposure rather than after the onset of symptoms [71].

The following drugs are useful for the prevention and/ or treatment of motion sickness [72].

\section{Anticholinergic Agents}

Scopolamine, an acetylcholine antagonist, is the most effective anti-motion-sickness agent presently available and is nonselective for the 5 types of muscarinic receptors found in the central nervous system. This agent's exact site and mechanism of action are not completely known, but it is believed to inhibit vestibular input to the vestibular nuclei and probably also acts directly on the vomiting center [73].

In recent decades, transdermal scopolamine was developed to provide effective prophylaxis and consistent serum levels over an extended period $(72 \mathrm{~h})[74,75]$. The patch is placed over the postauricular skin, the site of highest skin permeability [61]. By this route, a prophylactic effect is obtained 6-8 $\mathrm{h}$ after application. 
By the oral route, scopolamine is effective within $0.5 \mathrm{~h}$ for a period of $6 \mathrm{~h}$. Therefore, Nachum et al. [76] preferred the combination of transdermal and oral scopolamine $(0.3$ or $0.6 \mathrm{mg}$ ). This combination provides the required plasma levels to prevent seasickness, starting as early as $0.5 \mathrm{~h}$ after treatment, with no significant adverse effects.

Furthermore scopolamine nasal spray [77, 78] was found to be an effective and safe treatment in motion sickness, with a fast onset within 30 min after administration.

The anticholinergic side effects of scopolamine concern the ciliary muscle of the eye lens, the salivary and sweat glands, and the heart.

In 2011, a systematic Cochrane review [79] was performed to assess the effectiveness of scopolamine for preventing and treating motion sickness. Of 35 studies considered potentially relevant, 14 studies ( 1,025 subjects) met the entry criteria. Scopolamine was administered via transdermal patches, tablets or capsules, oral solutions or intravenously and was compared against placebo, calcium channel antagonists, antihistamines, methscopolamine or a combination of scopolamine and ephedrine. Scopolamine was more effective than placebo in preventing symptoms. Comparisons between scopolamine and other agents were few and suggested that scopolamine was superior (vs. methscopolamine) or equivalent (vs. antihistamines) as a preventative agent. Evidence comparing scopolamine to cinnarizine or combinations of scopolamine and ephedrine is equivocal or minimal. Although sample sizes were small, scopolamine was no more likely to induce drowsiness, blurry vision or dizziness compared to other agents. Dry mouth was more common with scopolamine than with methscopolamine or cinnarizine. No studies were available related to the therapeutic effectiveness of scopolamine in managing established motion sickness symptoms. The use of scopolamine versus a placebo in preventing motion sickness has been shown to be effective. No conclusions can be made on the comparative effectiveness of scopolamine and other agents, such as antihistamines and calcium channel antagonists. In addition, we identified no randomized controlled trials that examined the effectiveness of scopolamine in treating established motion sickness symptoms.

Gil et al. [80] observed a significant advantage of transdermal scopolamine over cinnarizine.

\section{Sympathomimetics (Catecholamine Activators)}

These agents are mainly used during space flights. A 5- to 10-mg oral dose of dextroamphetamine has been shown to magnify the prophylactic effects of scopolamine and antihistamines. The drug appears to act centrally by stimulating either dopaminergic or noradrenergic pathways.

Murray [75] concluded that a combination of scopolamine and dextroamphetamine seems to be the most effective anti-motion-sickness preparation. The most important side effect is the risk of drug dependence.

\section{Antihistamines}

The role of antihistamines in motion sickness treatment was discovered in 1949 [81]. A pregnant woman who was highly susceptible to motion sickness was given dimenhydrinate for urticaria. While taking this drug, she was immune to motion sickness.

Histamine increases the firing rate in afferent nerves from the ampullae of the semicircular canals. This effect is antagonized by various $\mathrm{H}_{1}$ receptor antagonists used as anti-motion-sickness agents [23].

The ability of dimenhydrinate to both prevent and treat motion sickness likely stems from its antihistaminic and anticholinergic properties. Wood et al. [82] analyzed 15 different works with at least 5,184 patients and found an effectiveness of antihistamines in motion sickness treatment of $70 \%$. The most common side effect was sedation.

Valoti et al. [83] evaluated diphenhydramine in the plasma of healthy volunteers after a single $25-\mathrm{mg}$ oral dose of dimenhydrinate (diphenhydramine theophyllinate), corresponding to $12.7 \mathrm{mg}$ diphenhydramine, in a chewing gum formulation. They found that the pharmaceutical formulation employed provided sustained plasma concentrations of diphenhydramine, presumably sufficient to support its clinical efficacy towards motion sickness owing to the almost complete (>95\%) release of the active principle by the formulation. Moreover, the maximal concentrations of diphenhydramine attained in plasma were significantly lower than the concentration threshold needed to produce drowsiness.

Furthermore, chlorpheniramine, which has the potential to be administered transdermally, was found to be effective against motion sickness [84]. Ephedrine does not increase the effectiveness of chlorpheniramine against motion sickness but successfully counteracts sedative and performance effects [85].

Weinstein and Stern [86] compared two popular antihistamines, dimenhydrinate (Dramamine) and cyclizine (Marezine), with regard to their anti-motion-sickness effects. They observed that Marezine and Dramamine are similarly effective in preventing the overall subjective symptoms of motion sickness. While Dramamine's effec- 
tiveness may be related to its sedative properties, Marezine may work more directly on the stomach and thus be more effective in preventing gastric dysrhythmias and reports of gastrointestinal symptoms.

Cheung et al. [87] investigated the effectiveness of two second-generation antihistamines (cetirizine and fexofenadine) in modulating motion sickness induced by coriolis vestibular cross-coupling stimulation in healthy adults. They found no significant differences between the baseline susceptibility to motion sickness and treatment with placebo, cetirizine or fexofenadine. Therefore, they concluded that the failure of these second-generation antihistamines to prevent motion sickness suggests that the therapeutic actions of this class of antihistamines against motion sickness may be mediated through central versus peripheral receptors. The sedative effect of other antihistamines, such as hydroxyzine, may play a more significant role in alleviating motion sickness than previously thought.

\section{Neuroleptics}

In the treatment of motion sickness, phenothiazine is primarily used; this treatment has a stronger sedative effect compared to antihistamines.

The effect is probably based on an antidopamine influence in the chemoreceptive emetic trigger zone [88].

Ramanathan et al. [89] evaluated two intranasal dosage forms of promethazine in dogs for absorption and bioavailability relative to that of an equivalent intramuscular dose. They found that the intranasal application of promethazine offers great promise as an effective, noninvasive alternative for treating space motion sickness due to its rapid absorption and bioavailability equivalent to that of the intramuscular dose.

Intramuscular injections of promethazine in 25 - or 50 $\mathrm{mg}$ doses are commonly used to treat space motion sickness in astronauts. Cowings at al. [90] examined the effects of intramuscular injections of promethazine on performance, mood states, and motion sickness in humans. Statistically significant decrements in performance were observed for both dosages of promethazine as compared with the placebo. They concluded that effective doses of promethazine currently used to counteract motion sickness in astronauts might significantly impair task components of their operational performance. Combination therapy with promethazine and caffeine has been proven effective in treating motion sickness and counteracting some possible side effects of using promethazine alone [91].
Dopamine Antagonists

Metoclopramide is a centrally acting antidopaminergic drug. Although metoclopramide is an effective antiemetic agent that enhances gastric emptying and prevents cancer chemotherapy-induced emesis, some studies [92, 93] have been unable to demonstrate any significant effects of this drug in the case of motion sickness. Only Rubio et al. [94] found metoclopramide to be more effective than diphenhydramine and placebo in the treatment of motion sickness.

\section{Serotonin (5- $\mathrm{HT}_{3}$ ) Receptor Antagonist}

The drugs ondansetron and granisetron are highly potent antiemetics. The serotonin $\left(5-\mathrm{HT}_{3}\right)$ receptor antagonists inhibit the development of gastric tachyarrhythmia but do not prevent the development of nausea and other motion sickness symptoms $[95,96]$. The antiemetics ondansetron and granisetron may act as gastric antidysrhythmics, but their ability to arrest the development of gastric tachyarrhythmia is not sufficient to prevent nausea [97].

\section{Serotonin (5-HT $1 \mathrm{~B} / 1 \mathrm{D})$ Receptor Agonist}

Motion sickness occurs in approximately $50 \%$ of migraine sufferers [98]. The effect of tryptophan depletion on motion sickness symptoms in migraineurs may be a hint that reduced brain serotonin activity may promote vestibule-ocular disturbances during motion sickness and migraine attacks [99].

Marcus and Furman [100] found that rizatriptan prevented the development of motion sickness and severe motion sickness symptoms in patients with migrainous vertigo. They suggest a possible role for serotonin in the development of motion sickness symptoms in migraineurs with migrainous vertigo. Furman et al. [101] postulated that the serotonin agonist rizatriptan reduces vestibulum-induced motion sickness by influencing serotonergic vestibulum-autonomic projections.

\section{Histaminergic Drugs}

Betahistine is an analog of L-histidine, the immediate precursor of histamine. It appears to have complex effects on histamine receptors, being a partial $\mathrm{H}_{1}$ postsynaptic agonist and an $\mathrm{H}_{3}$ presynaptic antagonist [23]. Betahistine's efficacy in treating different types of vertigo may be explained by its action in reducing the effects of the excess release of histamine that takes place in various areas of the brain, including the medial vestibular nucleus [102]. 
Gordon et al. [103] evaluated the effect of $48 \mathrm{mg}$ of betahistine on seasickness prevention in a laboratory and sea study.

They found no statistically significant effect of betahistine on seasickness in comparison with placebo and no notable side effects. In contrast, Matsnev and Sigaleva [104] demonstrated a significant positive influence of a 32-mg betahistine dihydrochloride dose compared to placebo on experimental motion sickness.

\section{Other Drugs}

The positive effects of phenytoin [105], the opioid loperamide [106], the $\mathrm{GABA}_{\mathrm{B}}$ agonist baclofen [107] and the neurokinin-1 receptor antagonist maropitant $[108,109]$ have been described.

Furthermore, the efficacy of the calcium antagonists flunarizine [110] and cinnarizine [70, 111, 112] was found. Whereas cinnarizine at a dose of $50 \mathrm{mg}$ was more effective than placebo at reducing symptoms in a doubleblind controlled placebo study, a $25-\mathrm{mg}$ dose was not [111].

Additionally, it was observed that ginsenosides combined with dexamethasone can significantly increase tolerance to acceleration in rats [113].

Although sailors used cocculus a hundred years ago to treat motion sickness symptoms, Lucertini et al. [114] did not find a significant effect of cocculus indicus (from Anamirta cocculus) compared to placebo with regard to simulator sickness symptoms.

The efficacy of ginger rhizome for the prevention of nausea, dizziness and vomiting, in the case of postoperative vomiting and vomiting during pregnancy, has been well documented and proved beyond a doubt in numerous high-quality clinical studies [115-118]. However, meta-analyses have not demonstrated an effect of ginger on the prevention or treatment of motion sickness [119].

With regard to the side effects of drugs against motion sickness, Gordon et al. [70] assessed the influence of dimenhydrinate $(100 \mathrm{mg})$, cinnarizine $(50 \mathrm{mg})$ and transdermal scopolamine on the ability to perform simulated naval crew tasks. The effect of single doses of dimenhydrinate, cinnarizine and one transdermal scopolamine patch on psychomotor performance was evaluated. Dimenhydrinate significantly impaired decision reaction time and auditory digit span. Most of the subjects who took dimenhydrinate also reported a subjective decrease in well-being and general performance abilities. Cinnarizine and transdermal scopolamine did not affect perfor- mance abilities. Cinnarizine was free of significant side effects. Dry mouth was the only significant side effect of transdermal scopolamine. These findings could be explained by the well-known sedative properties of dimenhydrinate and not by a specific effect on any particular cognitive or motor function.

These results suggest that $100 \mathrm{mg}$ of dimenhydrinate adversely affects psychomotor function, whereas single doses of cinnarizine at $50 \mathrm{mg}$ and transdermal scopolamine appear to be free of performance side effects and seem to be preferable antiseasickness drugs for use by naval crews. In contrast to these findings, Nicholson et al. [120] found that the calcium antagonist cinnarizine is not free of central activity over the usual therapeutic dose range of $15-30 \mathrm{mg}$. Therefore, they postulated that this drug is contraindicated for motion sickness treatment among aircrew involved in controlling aircrafts.

Paul et al. [121] investigated the impact of promethazine, meclizine, and dimenhydrinate on psychomotor performance and wanted to test whether the addition of pseudoephedrine or D-amphetamine to promethazine would ameliorate adverse effects. Their results showed that only promethazine plus D-amphetamine was free from impact on psychomotor performance and did not increase sleepiness.

Seibel et al. [122] compared 2 different formulations of dimenhydrinate, a single fast-release tablet and 3 chewing gums, with regard to their efficacy in a motion sickness model and their detrimental effect on vigilance and central nervous system performance. They observed that the objective measurements of vigilance and central nervous system performance showed significantly larger detrimental effects of the tablet than of the chewing gums. They concluded that this was probably a consequence of a faster increase in the dimenhydrinate concentration in the central nervous system after administration of the tablet in comparison to the divided dose principle of the chewing gums.

In sum, motion sickness has an important influence on modern travel activities and on the rapidly spreading field of virtual reality. Some evidence emphasizes the role of the otoliths in the pathogenesis of motion sickness. A few new theories may help explain motion sickness' occurrence beyond the traditional sensory conflict theory. A promising new direction is the recently reported association of a genetic polymorphism of the $\alpha_{2}$-adrenergic receptor with an increased autonomic response to stress and motion sickness. Some pharmacological and nonpharmacological countermeasures are used for the prevention and treatment of motion sickness. The nonphar- 
macological options include all procedures that reduce conflicting sensory input and accelerate the process of adaptation. The most effective anti-motion-sickness drugs are central acting anticholinergics, including scopolamine and $\mathrm{H}_{1}$ antihistamines. However, negative effects on psychomotor performance may limit these drugs' use among drivers, pilots and naval crew members. Recent studies may be relevant to find more information on the link between motion sickness, migraine, vertigo and anxiety. Based on these findings and on recent neurochemical data, the development of new anti-motion-sickness agents seems to be a promising field of investigation.

\section{References}

1 Brandt T, Daroff RB: The multisensory physiological and pathological vertigo syndromes. Ann Neurol 1980;7:195-203.

-2 Oosterveld WJ: Motion sickness. J Travel Med 1995;2:182-185.

-3 Wilson WD: Travel sickness in cattle. Vet Rec 1997;140:76.

-4 Kennedy RS, Graybiel A, McDonough RC, Beckwith FD: Symptomatology under storm conditions in the North Atlantic in control subjects and in persons with bilateral labyrinthine defects. Acta Otolaryngol 1968;66:533540.

5 Oman CM: Motion sickness: a synthesis and evaluation of the sensory conflict theory. Can J Physiol Pharmacol 1990;68:294-303.

-6 Reason JT: Motion sickness adaptation: a neural mismatch model. J R Soc Med 1978;71: 819-829.

7 Reason JT, Brand JJ: Motion Sickness. London, Academic Press, 1975.

8 Schmäl F, Stoll W: Kinetosen. HNO 2000;48: 346-356.

9 Parker DM: A psychophysiological test for motion-sickness susceptibility. J Gen Psychol 1971;85:87-92.

$\checkmark 10$ Money KE: Motion sickness. Physiol Rev 1970;50:1-39.

11 Oman CM: A heuristic mathematical model for the dynamics of sensory conflict and motion sickness. Acta Otolaryngol Suppl 1982; 392:1-44.

12 Pitman JR, Yolton RL: Etiology and treatment of motion sickness: a review. J Am Optom Assoc 1983;54:31-38.

13 Helling K, Hausmann S, Clarke A, Scherer H: Experimentally induced motion sickness in fish: possible role of the otolith organs. Acta Otolaryngol 2003;123:488-492.

14 Beier M, Anken RH, Rahmann H: Influence of hypergravity on fish inner ear otoliths. II. Incorporation of calcium and kinetotic behaviour. Adv Space Res 2002;30:727-731.

15 Hilbig R, Anken RH, Bauerle A, Rahmann H: Susceptibility to motion sickness in fish: a parabolic aircraft flight study. J Gravit Physiol 2002;9:29-30.

16 Diamond SG, Markham CH: Validating the hypothesis of otolith asymmetry as a cause of space motion sickness. Ann NY Acad Sci 1992;656:725-731.
17 Nooij SA, Vanspauwen R, Bos JE, Wuyts FL: A re-investigation of the role of utricular asymmetries in space motion sickness. J Vestib Res 2011;21:141-151.

18 Takabayashi A, Ohmura-Iwasaki T: Functional asymmetry estimated by measurements of otolith in fish. Biol Sci Space 2003; 17:293-297.

19 Xie SJ, Chen W, Jia HB, Wang ZJ, Yao Q, Jiang YY: Ocular vestibular evoked myogenic potentials and motion sickness susceptibility. Aviat Space Environ Med 2012;83:14-18.

-20 Tal D, Hershkovitz D, Kaminski G, Bar R: Vestibular evoked myogenic potential threshold and seasickness susceptibility. J Vestib Res 2006; 16:273-278.

21 Liu L, Yuan L, Wang HB, Yu LS, Zheng J, Luo CQ, Wang Y: The human alpha(2A)-AR gene and the genotype of site -1296 and the susceptibility to motion sickness (in Chinese). Sheng Wu Hua Xue Yu Sheng Wu Wu Li Xue Bao (Shanghai) 2002;34:291-297.

-22 Reavley CM, Golding JF, Cherkas LF, Spector TD, MacGregor AJ: Genetic influences on motion sickness susceptibility in adult women: a classical twin study. Aviat Space Environ Med 2006;77:1148-1152.

23 Shupak A, Gordon CR: Motion sickness: advances in pathogenesis, prediction, prevention, and treatment. Aviat Space Environ Med 2006;77:1213-1223.

24 Nashner LM, Peters JF: Dynamic posturography in the diagnosis and management of dizziness and balance disorders. Neurol Clin 1990;8:331-349.

25 Scherer H, Frohlich G: Reactions to coriolis stimulations and postrotatory ENG-response. A study on pilot-candidates and pilots. Acta Otolaryngol 1972;74:113-117.

26 Scherer H, Helling K, Hausmann S, Clarke $\mathrm{AH}$ : On the origin of interindividual susceptibility to motion sickness. Acta Otolaryngol 1997;117:149-153.

27 Klosterhalfen S, Kellermann S, Pan F, Stockhorst U, Hall G, Enck P: Effects of ethnicity and gender on motion sickness susceptibility. Aviat Space Environ Med 2005;76:10511057.

28 Jokerst MD, Gatto M, Fazio R, Gianaros PJ, Stern RM, Koch KL: Effects of gender of subjects and experimenter on susceptibility to motion sickness. Aviat Space Environ Med 1999;70:962-965.
29 Grunfeld E, Gresty MA: Relationship between motion sickness, migraine and menstruation in crew members of a 'round the world' yacht race. Brain Res Bull 1998;47:433-436.

30 Golding JF, Kadzere P, Gresty MA: Motion sickness susceptibility fluctuates through the menstrual cycle. Aviat Space Environ Med 2005;76:970-973.

31 Matchock RL, Levine ME, Gianaros PJ, Stern RM: Susceptibility to nausea and motion sickness as a function of the menstrual cycle. Womens Health Issues 2008;18:328-335.

32 Cheung B, Heskin R, Hofer K, Gagnon M: The menstrual cycle and susceptibility to coriolis-induced sickness. J Vestib Res 2001;11: 129-136.

33 McIntosh IB: Motion sickness - questions and answers. J Travel Med 1998;5:89-91.

34 Busoni P, Sarti A, Crescioli M, Agostino MR, Sestini G, Banti S: Motion sickness and postoperative vomiting in children. Paediatr Anaesth 2002;12:65-68.

35 Dichgans J, Brandt T: Visual-vestibular interaction in self-motion perception and postural control; in Teuber L, Held R, Leibowitz HW (eds): Handbook of Sensory Physiology. Springer Verlag Berlin Heidelberg, 1976, vol 5.

36 Fischer AJ, Oosterveld WJ: Motion sickness (author's transl). HNO 1979;27:285-291.

37 Yardley L: Motion sickness susceptibility and the utilisation of visual and otolithic information for orientation. Eur Arch Otorhinolaryngol 1990;247:300-304.

38 Wood R: The 'haunted swing' illusion. Psychol Rev 1895;2:277-278.

39 Kubo T, Matsunaga T, Matano S: Correlation between vestibular nuclei and the hypothalamus in the rat. Int J Equilib Res 1974;4:28-36.

40 Koch KL, Summy-Long J, Bingaman S, Sperry N, Stern RM: Vasopressin and oxytocin responses to illusory self-motion and nausea in man. J Clin Endocrinol Metab 1990;71:12691275.

41 Takeda N, Morita M, Kubo T, Yamatodani A, Watanabe T, Wada H, Matsunaga T: Histaminergic mechanism of motion sickness. Neurochemical and neuropharmacological studies in rats. Acta Otolaryngol 1986;101: 416-421.

42 Wang SC, Chinn H: Experimental motion sickness in dogs: functional importance of chemoreceptive trigger zone. Am J Physiol 1954;111-116.
Neuronal Mechanisms and Motion Sickness 
-43 Nicholson AN, Pascoe PA, Spencer MB, Benson AJ: Jet lag and motion sickness. Br Med Bull 1993;49:285-304.

-44 Griffin MJ, Newman MM: Visual field effects on motion sickness in cars. Aviat Space Environ Med 2004;75:739-748.

45 Golding JF, Prosyanikova O, Flynn M, Gresty MA: The effect of smoking nicotine tobacco versus smoking deprivation on motion sickness. Auton Neurosci 2011;160:53-58.

46 Yen Pik Sang FD, Billar JP, Golding JF, Gresty MA: Behavioral methods of alleviating motion sickness: effectiveness of controlled breathing and a music audiotape. J Travel Med 2003;10:108-111.

47 Ming JL, Kuo BI, Lin JG, Lin LC: The efficacy of acupressure to prevent nausea and vomiting in post-operative patients. J Adv Nurs 2002;39:343-351.

-48 Alkaissi A, Ledin T, Odkvist LM, Kalman S: P6 acupressure increases tolerance to nauseogenic motion stimulation in women at high risk for PONV. Can J Anaesth 2005;52:703709.

-49 Frey UH, Funk M, Lohlein C, Peters J: Effect of $\mathrm{P} 6$ acustimulation on post-operative nausea and vomiting in patients undergoing a laparoscopic cholecystectomy. Acta Anaesthesiol Scand 2009;53:1341-1347.

50 Frey UH, Scharmann P, Lohlein C, Peters J: P6 acustimulation effectively decreases postoperative nausea and vomiting in high-risk patients. Br J Anaesth 2009;102:620-625.

-51 Barsoum G, Perry EP, Fraser IA: Postoperative nausea is relieved by acupressure. J R Soc Med 1990;83:86-89.

52 Bertolucci LE, DiDario B: Efficacy of a portable acustimulation device in controlling seasickness. Aviat Space Environ Med 1995 66:1155-1158.

53 Bruce DG, Golding JF, Hockenhull N, Pethybridge RJ: Acupressure and motion sickness. Aviat Space Environ Med 1990;61:361-365.

- 54 O'Brien B, Relyea MJ, Taerum T: Efficacy of P6 acupressure in the treatment of nausea and vomiting during pregnancy. Am J Obstet Gynecol 1996;174:708-715.

55 Dundee JW, Sourial FB, Ghaly RG, Bell PF: P6 acupressure reduces morning sickness. J R Soc Med 1988;81:456-457.

56 Hu S, Stritzel R, Chandler A, Stern RM: P6 acupressure reduces symptoms of vection-induced motion sickness. Aviat Space Environ Med 1995;66:631-634.

-57 Stern RM, Jokerst MD, Muth ER, Hollis C: Acupressure relieves the symptoms of motion sickness and reduces abnormal gastric activity. Altern Ther Health Med 2001;7:91-94.

-58 Miller KE, Muth ER: Efficacy of acupressure and acustimulation bands for the prevention of motion sickness. Aviat Space Environ Med 2004;75:227-234

-59 Bertalanffy P, Hoerauf K, Fleischhackl R, Strasser H, Wicke F, Greher M, Gustorff B, Kober A: Korean hand acupressure for motion sickness in prehospital trauma care: a prospective, randomized, double-blinded tri- al in a geriatric population. Anesth Analg 2004;98:220-223.

60 Groen J: Adaptation. Pract Otorhinolaryngol 1957; 19:524

61 Ruckenstein MJ, Harrison RV: Motion sickness. Helping patients tolerate the ups and downs. Postgrad Med 1991;89:139-144.

62 Helling K, Westhofen M: Experimental studies of motion sickness on board of a research ship. HNO 1994;42:214-219.

63 Held R: Exposure history as a factor in maintaining stability of perception and co-ordination. J Nerv Ment Dis 1961;132:26-32.

64 Cha YH: Mal de débarquement. Semin Neurol 2009;29:520-527.

65 De Florio PT, Silbergleit R: Mal de débarquement presenting in the emergency department. J Emerg Med 2006;31:377-379.

66 Cha YH, Brodsky J, Ishiyama G, Sabatti C, Baloh RW: Clinical features and associated syndromes of mal de débarquement. J Neurol 2008;255:1038-1044.

67 Moeller L, Lempert T: Mal de débarquement: pseudo-hallucinations from vestibular memory? J Neurol 2007;254:813-815

68 Takeda N, Morita M, Horii A, Nishiike S, Kitahara T, Uno A: Neural mechanisms of motion sickness. J Med Invest 2001;48:44-59.

69 Wood CD, Graybiel A: A theory of motion sickness based on pharmacological reactions. Clin Pharmacol Ther 1970;11:621-629.

70 Gordon CR, Gonen A, Nachum Z, Doweck I, Spitzer O, Shupak A: The effects of dimenhydrinate, cinnarizine and transdermal scopolamine on performance. J Psychopharmacol 2001;15:167-172.

71 Murdin L, Golding J, Bronstein A: Managing motion sickness. BMJ 2011;343:d7430.

72 Schmäl F, Stoll W: Medikamentöse Schwindeltherapie. Laryngorhinootologie 2003;82: 44-61.

73 Matsuoka I, Ito J, Takahashi H, Sasa M, Takaori S: Experimental vestibular pharmacology: a minireview with special reference to neuroactive substances and antivertigo drugs. Acta Otolaryngol Suppl 1984;419:62-70.

74 Becker G, Goossens H, Seemann K, Souchon F, Weitz T: Prevention of motion sickness with a transdermal therapeutic system containing scopolamine. A randomized, comparative double-blind study in the German Federal Navy (in German). Dtsch Med Wochenschr 1984;109:1881-1885.

75 Murray JB: Psychophysiological aspects of motion sickness. Percept Mot Skills 1997;85: 1163-1167.

76 Nachum Z, Shahal B, Shupak A, Spitzer O, Gonen A, Beiran I, Lavon H, Eynan M, Dachir S, Levy A: Scopolamine bioavailability in combined oral and transdermal delivery. J Pharmacol Exp Ther 2001;296:121-123.

77 Klocker N, Hanschke W, Toussaint S, Verse $\mathrm{T}$ : Scopolamine nasal spray in motion sickness: a randomised, controlled, and crossover study for the comparison of two scopolamine nasal sprays with oral dimenhydrinate and placebo. Eur J Pharm Sci 2001;13:227-232.
78 Simmons RG, Phillips JB, Lojewski RA, Wang Z, Boyd JL, Putcha L: The efficacy of low-dose intranasal scopolamine for motion sickness. Aviat Space Environ Med 2010;81:405-412.

79 Spinks A, Wasiak J: Scopolamine (hyoscine) for preventing and treating motion sickness. CochraneDatabaseSystRev2011;6:CD002851.

80 Gil A, Nachum Z, Tal D, Shupak A: A comparison of cinnarizine and transdermal scopolamine for the prevention of seasickness in naval crew: a double-blind, randomized, crossover study. Clin Neuropharmacol 2012; 35:37-39.

81 Gray L, Carliner P: The prevention and treatment of motion sickness. Science 1949;109: 359

82 Wood CD, Kennedy RE, Graybiel A, Trumbull R, Wherry RJ: Clinical effectiveness of anti-motion-sickness drugs. Computer review of the literature. JAMA 1966;198:11551158.

83 Valoti M, Frosini M, Dragoni S, Fusi F, Sgaragli G: Pharmacokinetics of diphenhydramine in healthy volunteers with a dimenhydrinate $25 \mathrm{mg}$ chewing gum formulation. Methods Find Exp Clin Pharmacol 2003;25:377-381.

84 Buckey JC, Alvarenga D, Cole B, Rigas JR: Chlorpheniramine for motion sickness. J Vestib Res 2004;14:53-61.

85 Buckey JC Jr, Alvarenga DL, MacKenzie TA: Chlorpheniramine and ephedrine in combination for motion sickness. J Vestib Res 2007; 17:301-311.

86 Weinstein SE, Stern RM: Comparison of marezine and dramamine in preventing symptoms of motion sickness. Aviat Space Environ Med 1997;68:890-894.

87 Cheung BS, Heskin R, Hofer KD: Failure of cetirizine and fexofenadine to prevent motion sickness. Ann Pharmacother 2003;37:173177.

88 Stoot J: Mechanism and treatment of motion sickness; in Davis C, Lake Bakaar G, Grahame-Smith D (eds): Nausea and vomiting: mechanisms and treatment. Berlin, Springer, 1986.

89 Ramanathan R, Geary RS, Bourne DW, Putcha L: Bioavailability of intranasal promethazine dosage forms in dogs. Pharmacol Res 1998;38:35-39.

-90 Cowings PS, Toscano WB, De Roshia C, Miller NE: Promethazine as a motion sickness treatment: impact on human performance and mood states. Aviat Space Environ Med 2000;71:1013-1022.

91 Huang M, Gao JY, Zhai ZG, Liang QL, Wang YM, Bai YQ, Luo GA: An HPLC-ESI-MS method for simultaneous determination of fourteen metabolites of promethazine and caffeine and its application to pharmacokinetic study of the combination therapy against motion sickness. J Pharm Biomed Anal 2012;62:119-128.

92 Kohl RL: Failure of metoclopramide to control emesis or nausea due to stressful angular or linear acceleration. Aviat Space Environ Med 1987;58:125-131. 
-93 Oman CM, Lichtenberg BK, Money KE, McCoy RK: MIT/Canadian vestibular experiments on the Spacelab-1 mission. 4. Space motion sickness: symptoms, stimuli, and predictability. Exp Brain Res 1986;64:316334.

94 Rubio S, Weichenthal L, Andrews J: Motion sickness: comparison of metoclopramide and diphenhydramine to placebo. Prehosp Disaster Med 2011;26:305-309.

95 Hershkovitz D, Asna N, Shupak A, Kaminski G, Bar R, Tal D: Ondansetron for the prevention of seasickness in susceptible sailors: an evaluation at sea. Aviat Space Environ Med 2009;80:643-646.

-96 Muth ER, Elkins AN: High dose ondansetron for reducing motion sickness in highly susceptible subjects. Aviat Space Environ Med 2007;78:686-692.

-97 Levine ME, Chillas JC, Stern RM, Knox GW: The effects of serotonin $\left(5-\mathrm{HT}_{3}\right)$ receptor antagonists on gastric tachyarrhythmia and the symptoms of motion sickness. Aviat Space Environ Med 2000;71:1111-1114.

-98 Marcus DA, Furman JM, Balaban CD: Motion sickness in migraine sufferers. Expert Opin Pharmacother 2005;6:2691-2697.

99 Drummond PD: Effect of tryptophan depletion on symptoms of motion sickness in migraineurs. Neurology 2005;65:620-622.

100 Marcus DA, Furman JM: Prevention of motion sickness with rizatriptan: a doubleblind, placebo-controlled pilot study. Med Sci Monit 2006;12:I1-I7.

101 Furman JM, Marcus DA, Balaban CD: Rizatriptan reduces vestibular-induced motion sickness in migraineurs. J Headache Pain 2011;12:81-88.

102 Wang JJ, Dutia MB: Effects of histamine and betahistine on rat medial vestibular nucleus neurones: possible mechanism of action of anti-histaminergic drugs in vertigo and motion sickness. Exp Brain Res 1995;105:1824
103 Gordon CR, Doweck I, Nachum Z, Gonen A, Spitzer O, Shupak A: Evaluation of betahistine for the prevention of seasickness: effect on vestibular function, psychomotor performance and efficacy at sea. J Vestib Res 2003;13:103-111.

104 Matsnev EI, Sigaleva EE: Efficacy of histaminergic drugs in experimental motion sickness. J Vestib Res 2007;17:313-321.

105 Albert EG: Phenytoin for the prevention of motion sickness. Med J Aust 2003;178:575576.

106 Otto B, Riepl RL, Otto C, Klose J, Enck P, Klosterhalfen S: $\mu$-Opiate receptor agonists - a new pharmacological approach to prevent motion sickness? Br J Clin Pharmacol 2006;61:27-30.

107 Cohen B, Dai M, Yakushin SB, Raphan T: Baclofen, motion sickness susceptibility and the neural basis for velocity storage. Prog Brain Res 2008;171:543-553.

108 Conder GA, Sedlacek HS, Boucher JF, Clemence RG: Efficacy and safety of maropitant, a selective neurokinin 1 receptor antagonist, in two randomized clinical trials for prevention of vomiting due to motion sickness in dogs. J Vet Pharmacol Ther 2008;31:528532.

109 Hickman MA, Cox SR, Mahabir S, Miskell C, Lin J, Bunger A, McCall RB: Safety, pharmacokinetics and use of the novel NK-1 receptor antagonist maropitant (Cerenia) for the prevention of emesis and motion sickness in cats. J Vet Pharmacol Ther 2008;31: 220-229.

110 Lee JA, Watson LA, Boothby G: Calcium antagonists in the prevention of motion sickness. Aviat Space Environ Med 1986;57:4548.

111 Doweck I, Gordon CR, Spitzer O, Melamed Y, Shupak A: Effect of cinnarizine in the prevention of seasickness. Aviat Space Environ Med 1994;65:606-609.

112 Shupak A, Doweck I, Gordon CR, Spitzer O: Cinnarizine in the prophylaxis of seasickness: laboratory vestibular evaluation and sea study. Clin Pharmacol Ther 1994;55: 670-680.
13 Jia L, Wang WY, Zhou LM, Mo FF, Li M: Antimotion sickness effects of ginsenosides combined with dexamethasone in rats (in Chinese). Zhong Xi Yi Jie He Xue Bao 2010; 8:358-362.

114 Lucertini M, Mirante N, Casagrande M, Trivelloni P, Lugli V: The effect of cinnarizine and cocculus indicus on simulator sickness. Physiol Behav 2007;91:180-190.

115 Grontved A, Brask T, Kambskard J, Hentzer E: Ginger root against seasickness. A controlled trial on the open sea. Acta Otolaryngol 1988;105:45-49.

116 Holtmann S, Clarke AH, Scherer H, Hohn $\mathrm{M}$ : The anti-motion sickness mechanism of ginger. A comparative study with placebo and dimenhydrinate. Acta Otolaryngol 1989;108:168-174.

117 Mowrey DB, Clayson DE: Motion sickness, ginger, and psychophysics. Lancet 1982;i:655-657.

118 Lien HC, Sun WM, Chen YH, Kim H, Hasler W, Owyang C: Effects of ginger on motion sickness and gastric slow-wave dysrhythmias induced by circular vection. Am J Physiol Gastrointest Liver Physiol 2003; 284:G481-G489.

119 Chrubasik S, Pittler MH, Roufogalis BD: Zingiberis rhizoma: a comprehensive review on the ginger effect and efficacy profiles. Phytomedicine 2005;12:684-701.

120 Nicholson AN, Stone BM, Turner C, Mills SL: Central effects of cinnarizine: restricted use in aircrew. Aviat Space Environ Med 2002;73:570-574

121 Paul MA, MacLellan M, Gray G: Motionsickness medications for aircrew: impact on psychomotor performance. Aviat Space Environ Med 2005;76:560-565.

122 Seibel K, Schaffler K, Reitmeir P, Golly I: A randomised, placebo-controlled study comparing two formulations of dimenhydrinate with respect to efficacy in motion sickness and sedation. Arzneimittelforschung 2002; 52:529-536. 